\title{
Síndrome coronario agudo e insuficiencia mitral-aórtica grave en un paciente con rubeola congénita
}

\section{Acute coronary syndrome and mitral-aortic insufficiency in a patient with congenital rubella}

\author{
Daniela M. Sánchez-Romero*, Jaime G. López-Taylor, Miguel A. Medina-Andradre, \\ Carlos A. Jiménez-Fernández, Ítalo D. Masini-Aguilera y Dulman O. Pineda-De-Paz \\ Departamento de Tórax y Cardiovascular, Hospital Civil Fray Antonio Alcalde, Guadalajara, Jalisco, México
}

\begin{abstract}
Resumen
La rubeola es una enfermedad exantemática que se produce en la infancia. En caso de que se presente durante la gestación y hubiera afectación del producto, este puede desarrollar el síndrome de rubeola congénita, el cual incluye malformaciones cardiacas que se presentan en el $67 \%$ de los pacientes, de las cuales la más común es la persistencia del conducto arterioso, seguida de la estenosis valvular pulmonar y la comunicación interauricular. Se presenta el caso de un hombre de 20 años con diagnóstico de síndrome de rubeola congénita, quien desarrolló glaucoma congénito, insuficiencia aórtica grave, insuficiencia mitral grave y enfermedad miocárdica isquémica. Se realizó procedimiento quirúrgico de revascularización coronaria y recambio valvular mitral y aórtico. Los estudios encontrados durante el proceso de investigación mencionan el daño de los vasos sanguíneos y del miocardio producido por el virus. Con los datos obtenidos se corrobora la baja incidencia de presentación con compromiso coronario y valvular, por lo cual se hace énfasis en la importancia de este caso.
\end{abstract}

Palabras clave: Rubeola congénita. Malformación cardiaca. Isquemia coronaria. Insuficiencia mitral. Insuficiencia aórtica.

\section{Abstract}

Rubella is an exanthematous disease that occurs in childhood. If it occurs during pregnancy and there is an effect on the product, it can develop congenital rubella syndrome. The congenital rubella syndrome includes cardiac malformations, which occur in $67 \%$ of patients, of which the most common is patent ductus arteriosus, followed by pulmonary valvular stenosis and atrial septal defect. We present the case of a 20-year-old man with a diagnosis of congenital rubella syndrome, presenting with congenital glaucoma, severe aortic insufficiency, severe mitral regurgitation and ischemic myocardial disease. In which a surgical procedure is performed by a coronary revascularization and mitral and aortic valve replacement. Studies found during the research process mention the damage to the blood vessels and myocardium produced by the virus. With the required data, the low incidence of presentation with coronary and valvular involvement is corroborated, which is why the importance of the present case is emphasized.

Key words: Congenital rubella. Cardiac malformation. Ischemic myocardial disease. Mitral insufficiency. Aortic insufficiency.

\section{Correspondencia:}

*Daniela M. Sánchez-Romero

E-mail: daniela.sanchezr@ hotmail.com
Fecha de recepción: 30-10-2018

Fecha de aceptación: 03-08-2020

DOI: 10.24875/RCCAR.M21000054
Disponible en internet: 29-07-2021 Rev Colomb Cardiol. 2021;28(3):284-288 www.rccardiologia.com 0120-5633 / C 2020 Sociedad Colombiana de Cardiología y Cirugía Cardiovascular. Publicado por Permanyer. Este es un artículo open access bajo la licencia CC BY-NC-ND (http://creativecommons.org/licenses/by-nc-nd/4.0/). 


\section{Introducción}

La rubeola es una enfermedad exantemática que se produce en la infancia y es ocasionada por un virus de la familia Togaviridae del género rubivirus. Cuando ocurre en pacientes gestantes y afecta el producto, este puede desarrollar el síndrome de rubeola congénita, el cual altera la organogénesis y causa defectos cardiovasculares, sordera, catarata, retraso mental, retardo generalizado del crecimiento, alteraciones neurológicas, crecimiento visceral, ictericia, prematuridad y atresia de vías biliares, entre otras ${ }^{1}$. Las malformaciones cardiacas más comunes son la persistencia del conducto arterioso, la estenosis de la válvula pulmonar y la comunicación interauricular.

El virus de la rubeola produce efectos citotóxicos en los vasos sanguíneos fetales y en el miocardio, el sistema nervioso central y las células epiteliales del oído interno y los dientes. Este efecto citotóxico hace más propenso al paciente a un evento isquémico cardiaco, aun cuando esté en condiciones hemodinámicamente estables $^{2}$. Los reportes de lesiones valvulares aisladas o miocárdicas oscilan entre el $1 \%$ y el $2 \%{ }^{3}$.

\section{Presentación del caso}

Varón de 20 años, quien mediante interrogatorio indirecto refiere inicio de su padecimiento con disnea, dolor torácico en la región precordial de comienzo súbito, opresivo, no irradiado, el cual no mejoraba, e iba acompañado de disnea de medianos esfuerzos y vómito de contenido gastrobiliar. Entre los antecedentes de importancia se encuentran glaucoma congénito y madre con rubeola durante embarazo.

Acudió a la unidad hospitalaria, donde se observa elevación del segmento ST en V5 y V6, troponina de 1.94 y ecocardiograma transtorácico con acinesia anterolateral, inferolateral e inferior, motivo por el cual fue enviado a nuestra unidad por sospecha de síndrome coronario agudo.

Fue ingresado en la unidad de cuidados coronarios, donde se documentó choque cardiogénico que requirió ventilación mecánica invasiva. La troponina I fue $>30$. Posteriormente se realizó ecocardiograma, en el que se diagnosticó insuficiencia de válvula mitral grave, jet excéntrico que llegaba hasta las venas pulmonares, insuficiencia aórtica moderada, fracción de eyección del ventrículo izquierdo del $45 \%$, ventrículo izquierdo moderadamente dilatado y ventrículo derecho hipertrófico. Luego, mediante cateterismo cardiaco, se observó

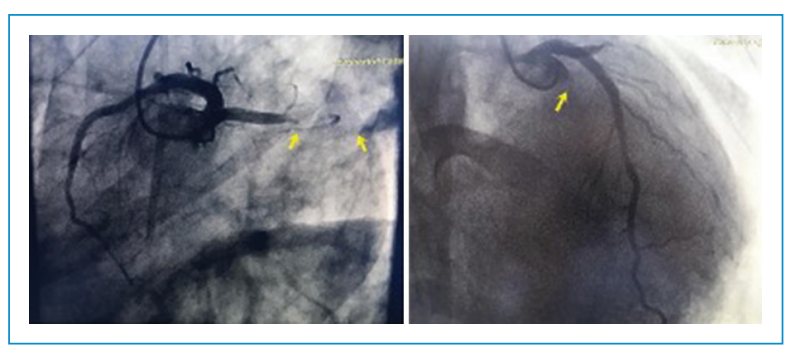

Figura 1. Obstrucción proximal del $100 \%$ de la arteria circunfleja, Ilena por flujo heterocoronario.

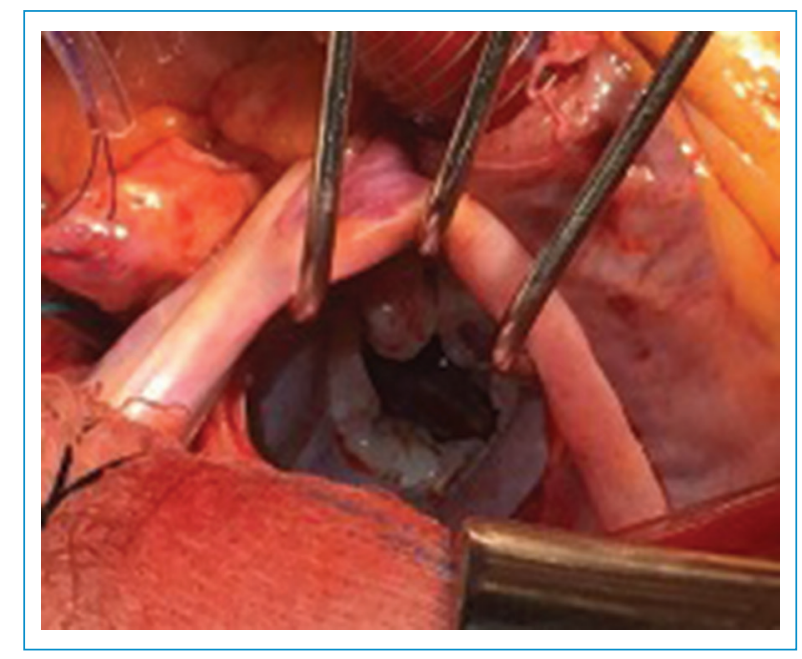

Figura 2. Válvula mitral con mala coaptación de valvas y hendiduras en valva anterior y posterior.

oclusión total de la arteria circunfleja en su porción proximal (Fig. 1).

Se decidió realizar procedimiento quirúrgico por esternotomía media; se hizo canulación de aorta, aurícula derecha y vena cava inferior, para iniciar protocolo de cardioplejía, durante el cual se encontró cardiomegalia de grado IV con predominio de cavidades derechas, válvula aórtica trivalva con defecto en la zona de coaptación de aproximadamente $1 \mathrm{~cm}$, obtuso marginal con zona de cicatrización, válvula mitral con insuficiencia grave, mala coaptación de valvas y hendiduras en valva anterior y posterior que asemejan subdividir la válvula en cuatro valvas (Fig. 2). Se procedió con anastomosis distal de obtuso marginal a vena safena reversa, y se hizo sutura continua (Fig. 3). Se realizó recambio por válvula aórtica mecánica St Jude 21 (Fig. 4) con puntos separados, seguido de recambio de válvula mitral con válvula mecánica St Jude 31 con sutura continua intermitente (Fig. 5), y 


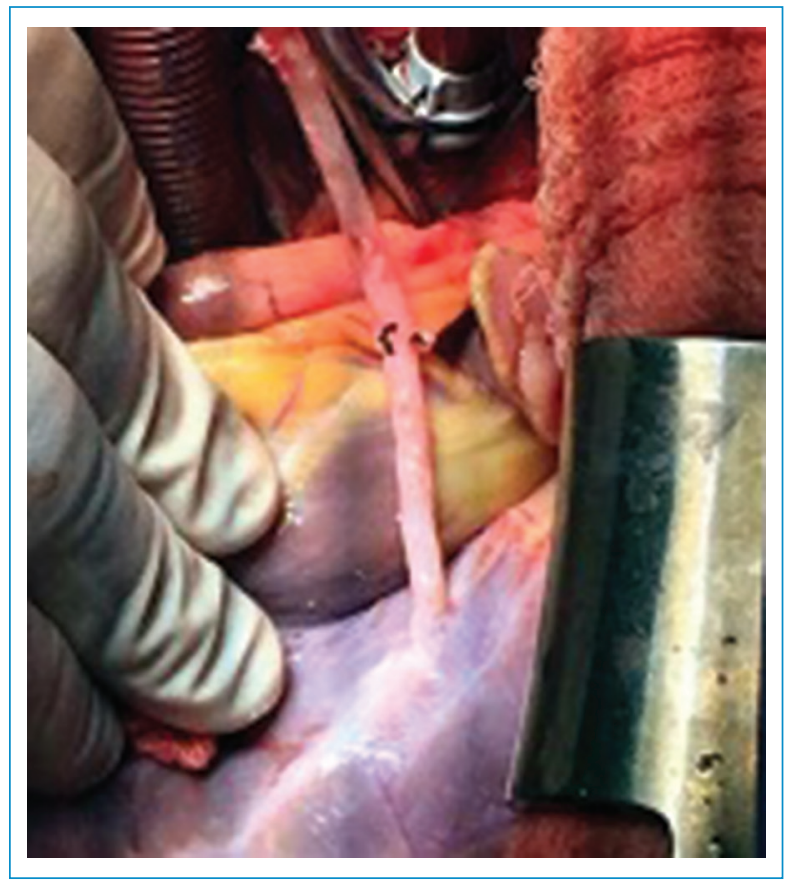

Figura 3. Anastomosis distal de ramo obtuso marginal a vena safena.

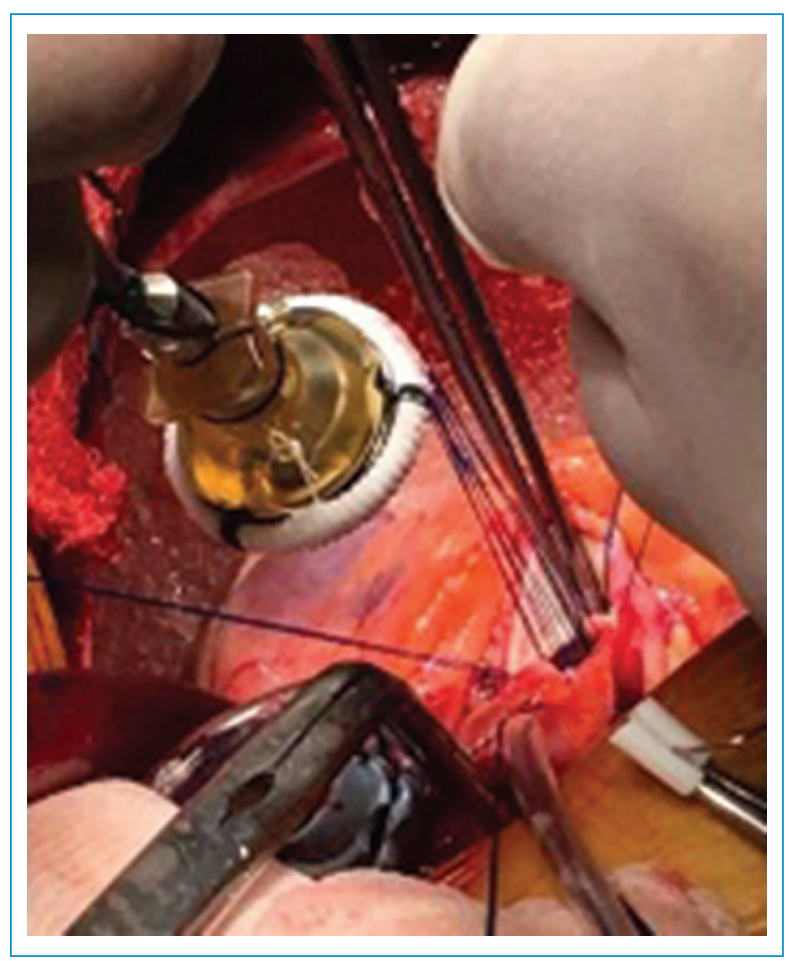

Figura 4. Colocación de válvula aórtica mecánica St. Jude 21.

posteriormente se inició el protocolo de salida de derivación cardiopulmonar.

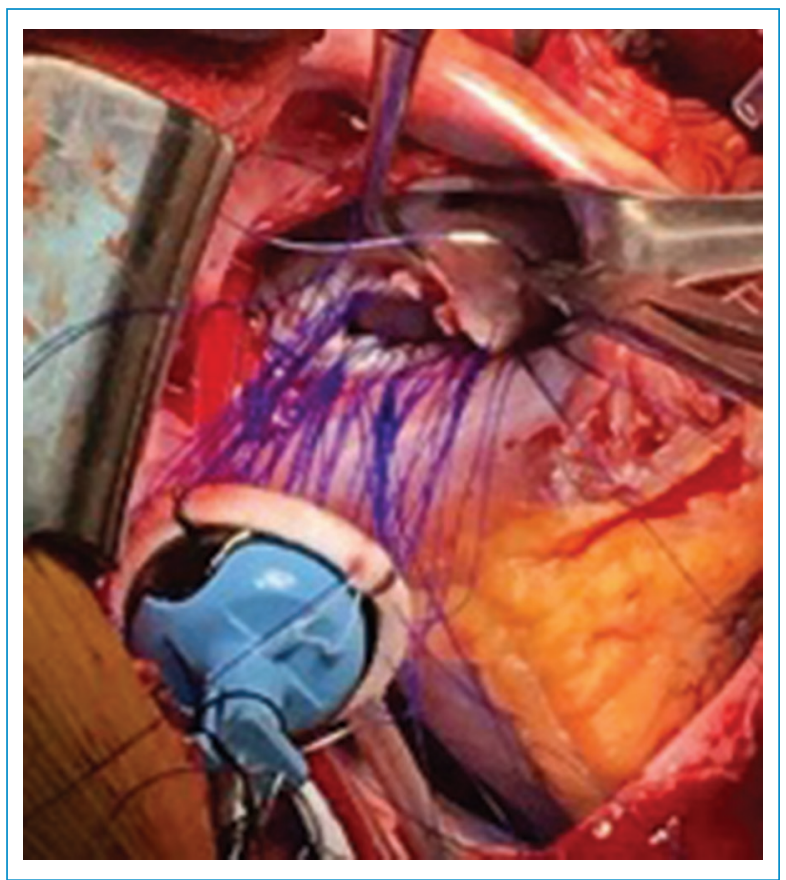

Figura 5. Colocación de válvula mitral mecánica St. Jude 31.

Durante el posquirúrgico presentó deterioro neurológico súbito mientras se encontraba en destete crónico del ventilador mecánico. Se realizó tomografía computarizada cerebral, que no evidenció lesión alguna. Requirió ventilación mecánica durante 11 días. Posterior al evento, se inició terapia de rehabilitación pulmonar y física, y tratamiento con anticoagulación oral con warfarina hasta lograr el INR (International Normalized Ratio) objetivo. En vista de su mejoría clínica, se decidió darle egreso.

\section{Discusión}

La rubeola es una enfermedad producida por un virus de la familia Togaviridae del género rubivirus, aislado por primera vez en 1962 por Paul P. Parkman'. El medio de transmisión son las secreciones faríngeas de personas con infección subclínica; sin embargo, el mecanismo de transmisión más frecuente es el contacto directo. Es una enfermedad exantemática que se produce en la infancia, pero también puede darse durante la gestación y afectar el producto. En este caso, el feto desarrolla síndrome de rubeola congénita, el cual altera la organogénesis y causa defectos cardiovasculares, sordera, catarata, retraso mental, retardo generalizado del crecimiento, 
alteraciones neurológicas, crecimiento visceral, ictericia, prematuridad y atresia de vías biliares, entre otras ${ }^{1}$. Las encuestas seroepidemiológicas en México han mostrado que aproximadamente el $20 \%$ de las mujeres en edad fértil son susceptibles a la rubeola ${ }^{4,5}$. A pesar de que en el esquema nacional de vacunación en México está presente la vacuna triple viral (sarampión-rubeola-parotiditis) y de que se realizan campañas de prevención en adolescentes y adultos jóvenes, existe un alto porcentaje de susceptibilidad a la infección.

Si se produce infección perinatal, existe una correlación entre la edad gestacional en la cual la madre adquirió la infección y el tipo de malformación que presentará el producto; las malformaciones cardiacas ocurren si la infección afecta en las primeras 8 semanas de gestación. Se desconoce la edad gestacional del inicio del cuadro exantemático en la madre del paciente, pero por la correlación de la clínica es posible asumir la etapa gestacional de presentación.

Las malformaciones cardiacas ocurren en un 67\% de los pacientes con rubeola congénita. Entre estas, la más común es la persistencia del conducto arterioso $(21 \%)$, seguida de la estenosis valvular pulmonar $(17 \%)^{1}$. De igual manera, no se encontraron casos similares con compromiso coronario asociados a rubeola en adultos.

El virus de la rubeola produce efectos citotóxicos en los vasos sanguíneos fetales, el miocardio, el sistema nervioso central y las células epiteliales del oído interno y los dientes. Este efecto citotóxico hace más propenso al paciente a un evento isquémico cardiaco, aunque esté en condiciones hemodinámicamente estables ${ }^{2}$, como podría haber sido el mecanismo de compromiso coronario en nuestro paciente.

En un estudio de una serie de 13 pacientes pediátricos con síndrome de rubeola congénita, tres tenían estenosis de la arteria coronaria, la cual involucraba las arterias coronarias derecha e izquierda en dos y la arteria coronaria derecha en uno $^{6}$.

La patogenia suele ser multifactorial, pero también se ha encontrado que la aceleración de la actina se inhibe por el virus de la rubeola, lo que conduce a una alteración de la mitosis celular y al desarrollo de células precursoras. Así mismo, el interferón y las citocinas parecen estar reguladas por un aumento de las células fetales infectadas, lo cual podría alterar el desarrollo y la diferenciación de células ${ }^{7}$, y apoyar la presentación vascular y valvular del paciente.
Se han reportado lesiones valvulares en pacientes con rubeola congénita, que generalmente se acompañan de persistencia del conducto arterioso o estenosis de la arteria pulmonar, o de ambas. Los reportes de lesiones valvulares aisladas o miocárdicas suponen entre el $1 \%$ y el $2 \% 3$.

Pese a que no se apreció estenosis pulmonar en el paciente del caso, con los datos obtenidos se corrobora la baja incidencia de compromiso coronario y valvular, por lo cual se hace énfasis en la importancia del caso que aquí se expone, así como en su utilización para futuras investigaciones y para la práctica sanitaria.

\section{Conclusiones}

El síndrome de rubeola congénita se desarrolla cuando ocurre infección por el virus de la rubeola durante la gestación y se altera la organogénesis del producto. Los estudios encontrados durante el proceso de investigación mencionan el daño en el desarrollo y la diferenciación de células y vasos sanguíneos producido por el virus. Debido a que son pocos los casos reportados con dicho compromiso en pacientes con síndrome de rubeola congénita, se decidió presentar este caso.

\section{Agradecimientos}

Los autores agradecen al servicio de terapia intensiva coronaria del Hospital Civil Fray Antonio Alcalde y al Departamento de Cardiología por su asistencia en la recopilación de la información del manejo posquirúrgico. A la Dra. Irma Niria Sánchez Góngora y a Claudia Torres Ruiz, por su asistencia en la obtención de datos, revisión y apoyo.

\section{Financiamiento}

No se requirió financiamiento.

\section{Conflicto de intereses}

No se presentó conflicto de intereses en el momento de realizar este artículo.

\section{Responsabilidades éticas}

Protección de personas y animales. Los autores declaran que para esta investigación no se han realizado experimentos en seres humanos ni en animales. 
Confidencialidad de los datos. Los autores declaran que han seguido los protocolos de su centro de trabajo sobre la publicación de datos de pacientes.

Derecho a la privacidad y consentimiento informado. Los autores han obtenido el consentimiento informado de los pacientes y/o sujetos referidos en el artículo. Este documento obra en poder del autor de correspondencia.

\section{Bibliografía}

1. Solórzano-Santos F. Infección perinatal por el virus de la rubéola en lactantes con cardiopatía congénita. Rev Med Inst Mex Seguro Soc. 2013;51:158-63.
2. Carmona F, Mata KM, Oliveira MS, Ramos SG. Myocardial ischemia in congenital heart disease: a review. En: Gaze DC, editor. Ischemic heart disease. Croatia: InTech; 2013. p. 15-39. Disponible en: http://librodigital. sangregorio.edu.ec/librosusgp/28909.pdf

3. Oster ME, Riehle-Colarusso T, Correa A. An update on cardiovascular malformations in congenital rubella syndrome Children's Healthcare of Atlanta, Emory University, Atlanta, Georgia National Center on Birth Defects and Developmental Disabilities, Centers for Disease Control and Prevention, Atlanta, Georgia. Birth Defects Research (Part A). 2010;88:1(8).

4 Hesarur V. A rare case of congenital rubella syndrome. J Indian Coll Cardiol. 2018;8:99-101.

5. Emmanouilides G. Pulmonary artery stenosis associated with ductus arteriosus following maternal rubella. Circulation. 1964;29:514-22.

6. Macías-Hernández AE, Ponce de León S, Muñoz-Barrett JM, López-Jiménez F, Cano-Castro A, Vera- Peña A, et al. Seroepidemiología de la rubéola en una población femenina en edad reproductiva en León, Guanajuato. Salud Publica Mex. 1993;35:339-44.

7. Gupta V, Verma S, Ramakrishnan S, Hote M, Seth S, Bhargava B. Congenital rubella syndrome presenting in adulthood with fatigue. Circulation. 2013;128:2542-5. 